DOI: $10.15393 / \mathrm{j} 3 . \operatorname{art} .2014 .2730$

V. V. STARKOV

\title{
VII PETROZAVODSK INTERNATIONAL CONFERENCE ON COMPLEX ANALYSIS AND APPLICATIONS (PICCAnA)
}

The VII Petrozavodsk International Conference on Complex Analysis and Applications took place on 29 June - 5 July 2014. This weekly event takes place every two years (last week of June - first week of July). Ye. P. Dolzhenko stands at the origins of this Conference. It was he who made effort to organize the first such Conference in 2002. That Conference can be called rather a school, because its main part was presented as a set of re-

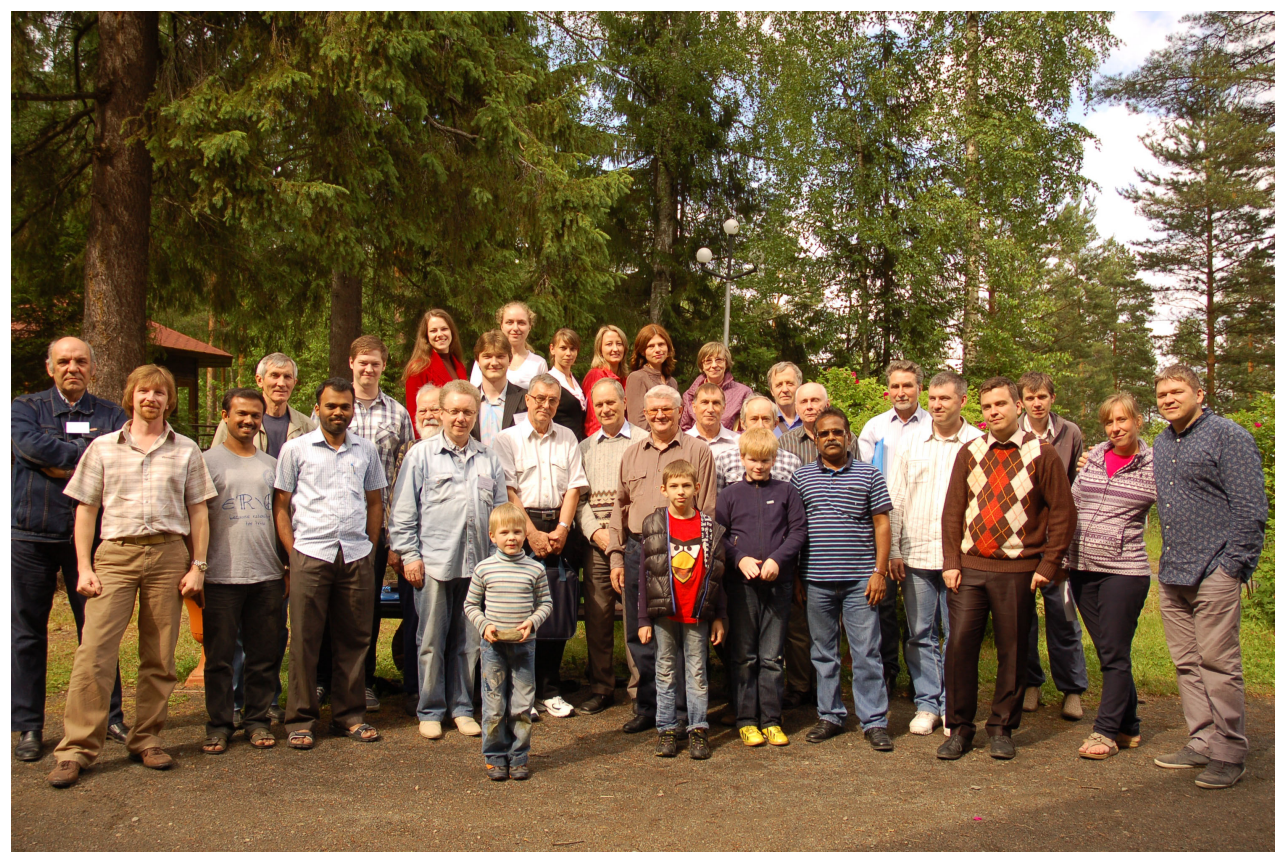

Participants of the VII conference

ports by Ye.P. Dolzhenko in the field of "Border behavior of analytical functions" and "Polyanalytic functions". There were no international 
scientists at the 2002 Conference. However, next conferences had a significant international attendance. Here in Petrozavodsk, we received mathematicians from Finland, Poland, Ukraine, the USA, Turkey and India. Russian scientists are substantially represented as well, as we say "from Moscow to the farthest borders".

The Conference traditionally takes place at the "Urozero" holiday center located on a tectonic lake in the picturesque suburb of Petrozavodsk.

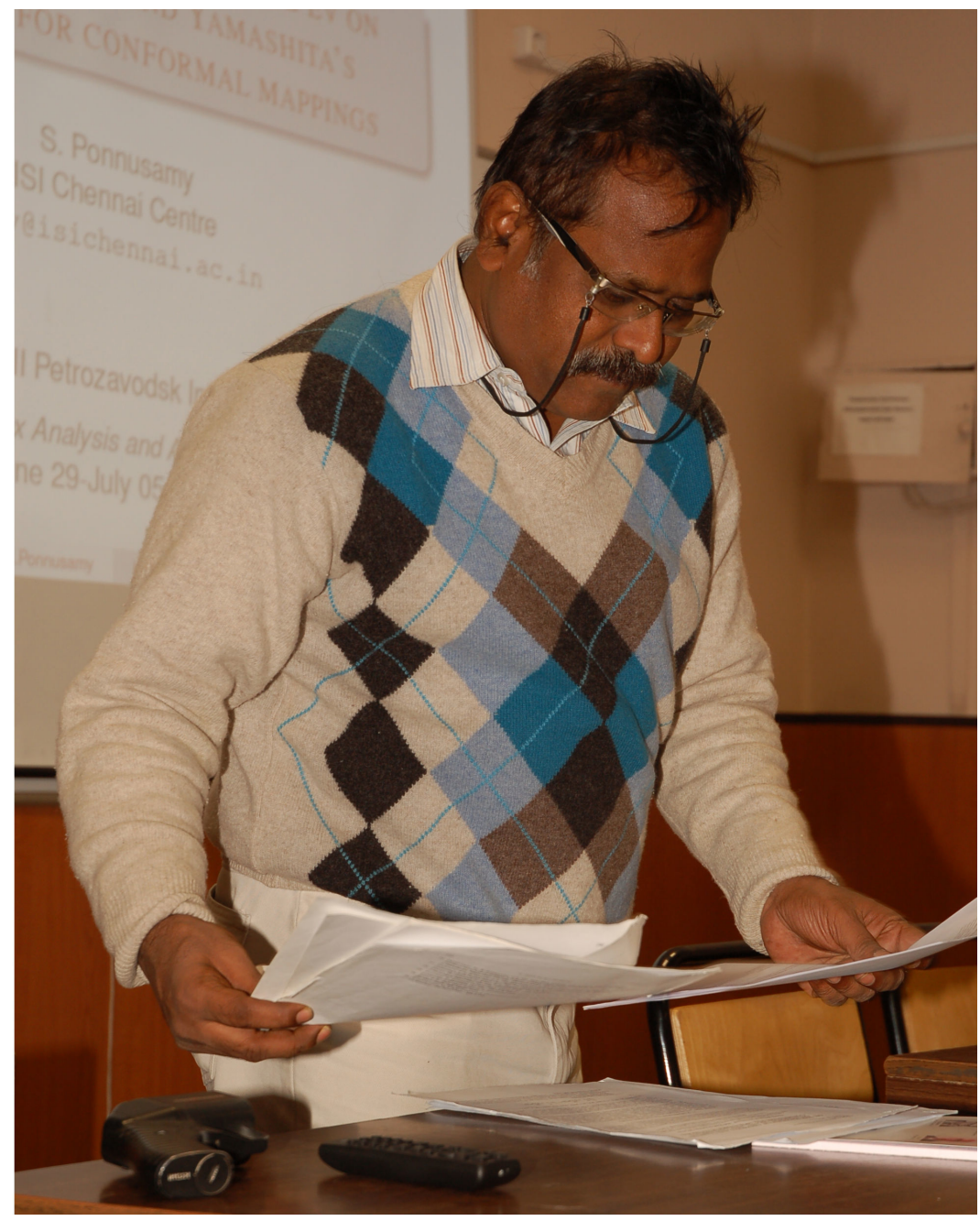

Professor S. Ponnusamy (Chennai, India)

As the participants say, the silence, the nature's beauty and the great environment significantly contribute to the fruitful work of the Conference. We always try to include tours around the marvelous surroun- 
dings in the event's schedule. Some participants take their fishing gear to go fishing in their free time; their catch is then prepared by the great cooks and served to the participants of the Conference.

The Conference has three areas of work:

- Geometric theory of functions of a complex variable;

- Constructive theory of functions of a complex variable, problems of the boundary behavior;

- Applications of analysis in mathematics and physics.

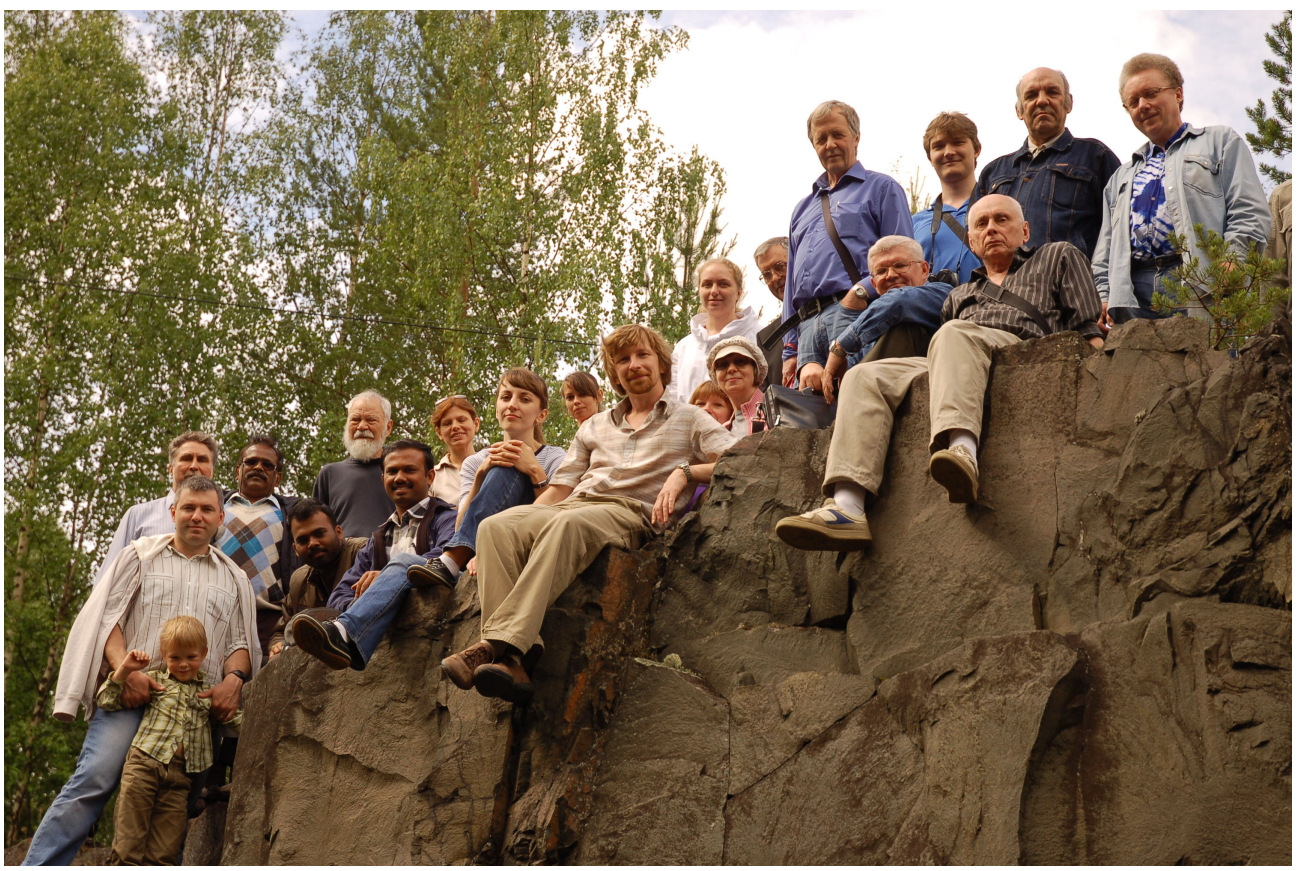

Participants of the VII conference on an excursion

In 2014, international organizing committee was represented by 15 people, with three Associate Members of the Russian Academy of Sciences. More than 60 people participated in the Conference: among them 25 PhDs, 15 Candidates, 14 postgraduate students and 3 students. Participants of the Conference were able to publish short presentations of their reports (up to five pages) in the "Conference Materials" section; Conference materials are downloaded to the Russian Science Citation Index database. Additional information can be found at http://mf.karelia.ru/piccana/.

At the penultimate day of the Conference, a "Problem solving session" was organized, where each participant had an opportunity to present interesting and important issues from his or her point of view. Many professors 
participated in the session, among them: S. R. Nasyrov, S. V. Kislyakov, N. A. Shirokov, F. N. Garifyanov, P. A. Borodin, I. R. Kayumov, A. G. Losev, S. Ponnusamy, V. V. Starkov, and Docent O. N. Kosukhin. Working languages of the Conference are Russian and English; however, conference materials were published in English. To mark the end of the VII Petrozavodsk International Conference on Complex Analysis and Applications, it is important to mention the strong interest of the world science in the presented topics, as well as the interest of the Conference's participants in the further scientific cooperation. According to the presented reports, today we see apparent ties between different scientific schools and research areas. Given the importance and the practical value of the Conference, it was decided to organize the next VIII Petrozavodsk International Conference on Complex Analysis and Applications in 2016.

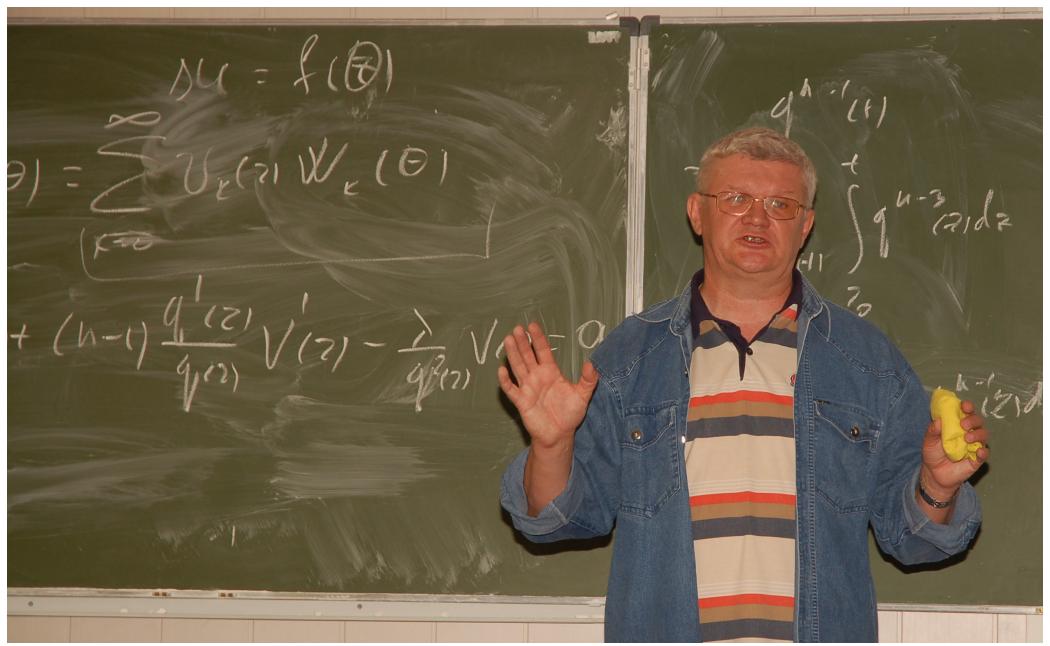

Report of Prof. A. G. Losev (Volgograd, Russia)

Acknowledgment. It wouldn't be possible to organize the VII Petrozavodsk International Conference on Complex Analysis and Applications without financial support of the Petrozavodsk State University (Program of Strategic Development of Petrozavodsk State University) and the Russian Found for Basic Research (project No 14-01-06004). We would like to express our gratitude for their support.

Received September 1, 2014.

Petrozavodsk State University

33, Lenina st., 185910 Petrozavodsk, Russia

E-mail:vstarv@list.ru 